\title{
In-vitro Seeding of Bladder Smooth Muscle Cells onto Bladder Acellular Matrix as Cell Delivery Vehicle in Tissue Engineering
}

\author{
Rukmani Dewangan ${ }^{1}$, A. K. Sharma ${ }^{2}$, Naveen Kumar ${ }^{3}$ \\ Division of Surgery, Indian Veterinary Research Institute, Izatnagar 243 122, U.P., India
}

\begin{abstract}
The present study was carried out evaluated efficacy of bladder acellular matrix (BAM) as cell delivery vehicle. Smooth muscle cells were harvested by collagenase digestion of rabbit urinary bladder and the cells were cultured in growth medium comprising of 4:1 mixture of DMEM and Ham's F-12 nutrient mixture supplemented with L-glutamine containing $100 \mathrm{mg} / \mathrm{ml}$ penicillin as well as $100 \mathrm{mg} / \mathrm{ml}$ streptomycin. Fetal bovine serum was added @ 10\%. The isolated cells were cultured in-vitro to expand into sufficient number for seeding onto xenogenic bladder acellular matrix. Successful in-vitro seeding of bladder smooth muscle cells onto bladder acellular matrix was done.
\end{abstract}

Keywords: Bladder, Cell culture, Acellular matrix, BAM, Smooth muscle cells

\section{Introduction}

Tissue engineering including the use of matrices for tissue regeneration and selective cells for transplantation has provided a new approach to create functional organs or tissue segments. Cell therapy is a widely applicable therapeutic approach using cells and cell aliment for their beneficial effects. Cell transplantation may be beneficial for successful creation of functional urological tissue for bladder augmentation. Bladder acellular matrix (BAM) is a xenogenic collogen rich membrance. The proliferation and differentiation of cultured urothelium cells on bladder acellular biomaterials was done (Ram-Liebig et al., 2004) and the urothelium cell facilitated the recruitment and transdifferentiation of fibroblasts into smooth muscle in bladder acellular matrix (Master et al., 2003). Various synthetic biodegradable polymers can act as delivery vehicles for urothelial and bladder smooth muscle cells (Atala et al., 1993; Oberpenning et al., 1999). The bladder acellular matrix (BAM) acted as a substrate for studying in-vitro bladder smooth muscle-urothelial cell interactions (Brown et al., 2005) and was successfully repopulated with multilayers of ingrowing SMCs and superficial UCs (Schultheiss et al., 2005). Therefore, BAM was found to act as a cell deliverer in tissue engineering (Geng et al., 2006). In this study, invitro growth of bladder smooth muscle cells was seeded onto the xenogenic bladder matrix (BAM) was done in order to demonstrate relation between smooth muscle cells in conjunction with bladder acellular matrix necessary for the recruitment of host cells to repopulate the graft and evaluated efficacy of bladder acellular matrix as cell delivery vehicle.

\section{Materials and Methods}

a) Primary culture of bladder smooth muscle cells (SMCs)

Urinary bladder smooth muscle cells of rabbit were cultured as per the modified method of Atala et al. (1993) and Geng et al. (2006). The rabbit bladder was excised using combination of xylazine $(5 \mathrm{mg} / \mathrm{kg}$ ) and ketamine $(45 \mathrm{mg} / \mathrm{kg})$ intramuscular injection and rinsed in sterile Hank's balanced salt solution (HBSS) (Hi Media Laboratories Pvt. Ltd., India). Under sterile condition the bladder specimen was dissected and was minced into small pieces of approximately $1 \mathrm{~mm}^{3}$ fragments with help of scissor. Bladder fragments were digested in a $0.25 \%$ solution of collagenase Type-IV-S (Lifecare Pvt. Ltd., India) obtained from Clostridium histolyticum and incubated at $37^{\circ} \mathrm{C}$ for 30 min. Cell suspensions was then filtered with help of muslin cloth in $100 \mathrm{ml}$ beaker. The filtered solution was centrifuged at 2,000 rpm. The supernatant was discarded and the cell pellets were repeatedly washed twice with HBSS solution. Verification of cell pellets was done by examining aliquots of the final cell suspension microscopically on a hemocytometer. Efficiency of cell recovery and cell viability was determined using the trypan blue exclusion method and cells were counted and then transferred in tissue culture flask. The cell pellets were resuspended in 4:1 mixture of Dulbecco's modified eagle's medium (DMEM) (Hi Media Laboratories Pvt. Ltd., India, AT 067_01) and Ham's F-12 nutrient mixture with L-glutamine (Gibco, 11765) containing $100 \mathrm{mg} / \mathrm{ml}$ penicillin and $100 \mathrm{mg} / \mathrm{ml}$ streptomycin with 10\% fetal bovine serum (FBS) (Sigma Aldrich Co., St Louis). The cells were incubated in a humidified $\mathrm{CO}_{2}$ incubator containing $5 \% \quad \mathrm{CO}_{2}$ and maintained at $37^{\circ} \mathrm{C}$. The cells in cultures were left undisturbed for 1 week to promote its expansion. The media was changed twice a week and $\mathrm{pH}$ of medium was maintained and at the same time the muscle cell cultures were also examined until 80\% confluence was achieved. Once the cell growth in the culture flasks reached a $90 \%$ confluence, the medium was removed and then expanded smooth muscle cells were trypsinized, washed and collected as a pellet. The cells were then seeded onto porcine bladder acellular matrix (BAM).

\section{b) Preparation of porcine bladder acellular matrix} (BAM)

The urinary bladder of pig was procured from local abattoir in ice cold sterile phosphate buffered saline (PBS, pH 7.4) solution. It was rinsed with PBS to remove the adhered blood and maximum time period between the retrieval and 


\section{International Journal of Science and Research (IJSR) \\ ISSN (Online): 2319-7064 \\ Index Copernicus Value (2013): 6.14 | Impact Factor (2015): 6.391}

initiation of protocols was less than $4 \mathrm{~h}$. The tissues were cut into $2 \times 2 \mathrm{~cm} 2$ pieces and were directly treated with $0.5 \%$ sodium dodecyl sulphate (SDS) for $24 \mathrm{~h}$ under constant agitation at $180 \mathrm{rpm}$ at $37^{\circ} \mathrm{C}$ in the orbital shaker to provide better contact of tissue. Then, the tissue was washed thoroughly in PBS solution and stored in PBS solution containing $0.1 \%$ amikacin at $-20^{\circ} \mathrm{C}$ until use.

\section{c) Seeding of bladder smooth muscle cells onto porcine BAM}

Seeding on bladder acellular matrix was done as per the method of Brown et al. (2005). BAMG were cut to fit the wells of 24 well culture plates and soaked in series of $70 \%$ ethanol rinse. These grafts were re-hydrated in sterile PBS containing $1 \%$ penicillin-streptomycin for $24 \mathrm{~h}$ and then equilibrated in DMEM for $48 \mathrm{~h}$ prior to seeding at $37^{\circ} \mathrm{C}$ in a humidified atmosphere of $5 \% \mathrm{CO}_{2}$. On the day of seeding, a $90 \%$ confluency reached smooth muscle cells were trypsinized and washed. The cells were seeded onto the BAMG at concentration of $1 \times 10^{5}$ to $1 \times 10^{7}$ cells per $\mathrm{cm}^{2}$ and thereafter, $500 \mu \mathrm{l}$ of DMEM with $10 \%$ fetal bovine serum containing $100 \mathrm{mg} / \mathrm{ml}$ penicillin and $100 \mathrm{mg} / \mathrm{ml}$ streptomycin was carefully pipetted down to the cell-matrix complexes. All culture were incubated at $37^{\circ} \mathrm{C}$ in a humidified atmosphere of $5 \% \mathrm{CO}_{2}$ and allowed to attach for upto 7 days. Once the cells were seeded onto the BAMG, the medium was changed daily.

\section{Results}

a) Primary culture of bladder smooth muscle cells (SMCs)

Bladder smooth muscle cells displayed a spindle shaped feature with a centrally located nucleus. After 4 to 5 days of seeding, the cell reached $60 \%$ confluency and exhibited different morphological pattern like fusiform, triangular and stellate shapes, characteristic of smooth muscle cells (Fig. 1 ). On $7^{\text {th }}$ day post seeding, nuclear fission was evident and cell population achieved about $90 \%$ confluency. In this state, smooth muscle cells displayed an elongated, spindle shaped morphology with a centrally located nucleus and cell borders appeared to be straight and well defined (Fig. 2-3). The cells became fusiform and cell nodules formed a typical structure of multiple layers with a "hills and valleys" appearance (Fig. 4). When viewed in phase contrast and differential interference contrast (DIC) microscopy, 3 dimensional spindle shaped morphology of smooth muscle cells were evident (Fig. 5 A \& B). This type of morphology of cells was characteristically seen at about 7 day post seeding.

\section{b) Macroscopic and microscopic observation of porcine bladder acellular matrix (BAM)}

Bladder acellular matrix grafts was soft and spongy in consistency and slightly whiter than original tissue. The acellularity of prepared BAM was confirmed histologically which showed complete acellularity with normal collagen fibres arrangement (Fig. 6 A \& B) The nucleus and cytoplasmic cellular components were successfully removed with no evidence of remaining cells, nuclei or other cell fragments. c) Seeding of bladder smooth muscle cells onto porcine BAM

The bladder smooth muscle cells cultured in-vitro were seeded onto bladder acellular matrix and incubated in DMEM with $10 \%$ fetal bovine serum containing $100 \mathrm{mg} / \mathrm{ml}$ penicillin and $100 \mathrm{mg} / \mathrm{ml}$ streptomycin at $37^{\circ} \mathrm{C}$ in a humidified atmosphere and $5 \% \mathrm{CO}_{2}$. The $\mathrm{pH}$ of the culture medium decreased after 1 to 2 days of seeding, indicative of vigorous cell metabolism and progressive proliferation of the seeded cells. When viewed under microscopy, in 4-5 days, growth of smooth muscle cells with spindle shaped morphology was seen at the surface of the bladder acellular matrix graft and adhered to it. One week after seeding, a majority of smooth muscle cells were confined to the matrix surface.

\section{Discussion}

Tissue engineering technology had been proposed as an alternative approach to generate bladder tissues for reconstruction. Tissue engineering including the use of matrices for tissue regeneration and selective cells for transplantation has provided a new approach to create functional organs or tissue segments. The engineered scaffold must provide optimal structural integrity to withstand in-vivo requirements and provide appropriate regulation of cell behaviour (Atala, 2000). Acellular matrix, which is mainly made of the supporting connective tissue, has been widely studied as a biodegradable scaffold for tissue regeneration. Belonging to group of biomaterials, recently the homologous and heterologous BAMG has been demonstrated to serve as a scaffold for the ingrowth of all bladder wall components in the rat (Piechota et al., 1998 a; Piechota et al., 1998 b). Bladder acellular matrix graft is collagen-based non-immunogenic membranes derived from homologous or heterologous tissues. The bladder acellular matrix permits the regeneration of native epithelium acting as a scaffold, allowing cross-healing of the edges and also promoting angiogenesis and growth of smooth muscle bundles (Sutherland et al., 1996). Cell-seeded techniques need to seed biodegradable materials in-vitro the culturally expanded cells that are harvested from the host tissue and to form the complex patch (Yang et al., 2005). This composite structure will be placed back to the host to continue the regenerative process and finish the replacement. During this method, the biomaterial used as cell delivery vehicle is one of the key structures. Various synthetic biomaterials including polyglycolic acid (PGA), polylactic acid (PLA) and polylacticglycolic acid (PLGA) have been used experimentally with excellent biocompatibility (Pariente et al., 2002). But these synthetic materials also have some shortcomings, like expensiveness, lower elasticity, and unsuitability for surgical suture. Thus, the collagen-based material derived from the bladder has been taken as a cell deliverer. Since this naturally derived matrix is obtained from normal tissue, it provides an environment and framework that are more conducive to the regeneration process than that of synthetic material. They contain numerous factors that are likely to be critical to the induction of tissue regeneration (Geng et al., 2006). Other investigators have performed in-vitro studies using primary bladder cell culture techniques for the examination of smooth muscle and urothelial cell physiology. However, the 


\section{International Journal of Science and Research (IJSR) \\ ISSN (Online): 2319-7064}

Index Copernicus Value (2013): 6.14 | Impact Factor (2015): 6.391

majority of these studies have been carried out on tissue culture polystyrene or other rigid, three-dimensional (3-D) coated surfaces (Baskin et al., 1993 ; Hutton et al., 1993) These substrates differ significantly from the extracellular matrix surrounding in-situ bladder cells. In present study, invitro growth of rabbit bladder smooth muscle cells seeded onto xenogenic BAM in order to demonstrate the reaction between bladder smooth muscle cells and BAM, and the possible use of BAM as a cell deliverer in tissue engineering was evaluated. The cultured smooth muscle cells were applied for seeding cells onto the bladder acellular matrix graft. Brown et al. (2005) have reported the ability of BAM to support the individual and combined growth of porcine bladder SMCs and UECs. Lai et al. (2002) observed that tissue-engineered bladder smooth muscle cells seeded either on PGA polymer or collagen matrix still retain the contractile phenotype both in-vitro and in-vivo in a mice model.

In the present study, smooth muscle cells were harvested by collagenase digestion of rabbit urinary bladder. The cells were cultured in growth medium comprising of 4:1 mixture of DMEM and Ham's F-12 nutrient mixture supplemented with L-glutamine containing $100 \mathrm{mg} / \mathrm{ml}$ penicillin as well as 100 mg/ml streptomycin. Fetal bovine serum was added @ $10 \%$ to provide nutrient growth factors for cell proliferation. The cells in culture were allowed to grow for a week and the media was changed twice a week in order to remove the dead cells and cell debris. The $\mathrm{pH}$ of medium was maintained. The isolated cells were cultured in-vitro to expand into sufficient number for seeding onto xenogenic bladder acellular matrix (Atala et al., 1993; Geng et al., 2006). Smooth muscle cells were cultured and passaged by routine method. After 4 to 5 days of post seeding, cells exhibited different morphological pattern like fusiform, triangular and stellate shapes, characteristic of smooth muscle cells. In the confluent state, smooth muscle cells displayed an elongated, spindle shaped morphology with a centrally located nucleus (Brown et al., 2005). The cells became fusiform and cell nodules formed a typical structure of multiple layers with a "hills and valleys" appearance (Lai et al., 2005; Geng et al., 2006). The bladder smooth muscle cells cultured in-vitro were seeded onto bladder acellular matrix (Brown et al., 2005) and after 4-5 days, growth of smooth muscle cells with spindle shaped morphology were seen at the surface of the bladder acellular matrix matrix. Bladder smooth muscle cells were found to adhere to the BAM, penetrate into the matrix, and expand in it after cell seeding. One week after seeding, a majority of smooth muscle cells were confined to the matrix surface. This finding revealed that the BAM can be used as a cell deliverer in tissue engineering.

It can be concluded that successful in-vitro seeding of bladder smooth muscle cells onto xenogenic bladder acellular matrix was done and smooth muscle cells in conjunction with bladder acellular matrix are necessary for the recruitment of host cells to repopulate the graft and seeded BAM could be used as a cell deliverer in tissue engineering.

\section{References}

[1] Atala, A. (2000 ). New methods of bladder augmentation. Br J U Int 85 (Suppl.3): 24-34.

[2] Atala, A.; Freeman, M. R.; Vacanti, J. P.; Shepard, J. and Retik, A. B. (1993). Implantation in-vivo and retrieval of artificial structures consisting of rabbit and human urothelium and human bladder muscle. J Urol 150(2): 608-612.

[3] Baskin, L. S., Howard, P. S. and Macarack, E. J. (1993 ). Effect of physical forces on bladder smooth muscle and urothelium. J Urol 150: 601-607.

[4] Brown, A. L.; Brook-Allred, T. T.; Waddell, J. E.; White, J.; Wermeister, J. A.; Ramshaw, J. A. M.; Bagli, D. J. and Woodhouse, K. A. (2005). Bladder acellular matrix as a substrate for studying in-vitro bladder smooth muscle-urothelial cell interactions. Biomaterials 26: 529-543.

[5] Geng, H. Q.; Tang, D. X.; Chen, F.; Wu, X. R. and Zhou, X. (2006). The bladder submucosa acellular matrix as a cell deliverer in tissue engineering. World $J$ Pediatr 2(1): 57-60.

[6] Hutton, K. A. R.; Trejdosiewiez, L. K.; Thomas, D. F. M. and Southgate, J. (1993). Urothelial tissue culture for bladder reconstruction: An experimental study. $J$ Urol 150 (2): 721-725.

[7] Lai, J. Y.; Chang, P. Y. and Lin, J. N. (2005). Bladder autoaugmentation using various biodegradable scaffolds seeded with autologous smooth muscle cells in a rabbit model. J Pediatr Surg 40: 1869-1873.

[8] Lai, J. Y.; Yoon, C. Y. and Yoo, J. J. (2002). Phenotypic and functional characterization of in-vivo tissue engineered smooth muscle from normal and pathological bladders. J Urol 168: 1853-1858.

[9] Master, V. A.; Wei, G.; Liu, W. and Baskin, L. S. (2003). Urothelium facilitates the recruitment and transdifferentiation of fibroblasts into smooth muscle in acellular matrix. J Urol 170(10): 1628-1632.

[10] Oberpenning, F.; Meng, J.; Yoo, J. J. and Atala, A. (1999). De novo reconstitution of a functional mammalian urinary bladder by tissue engineering. Nat Biotech 17: 149-155.

[11] Pariente, J. L.; Kim, B. S. and Atala, A. (2002). In-vitro biocompatibility evaluation of naturally derived and synthetic biomaterials using normal human bladder smooth muscle cells. J Urol 167(4): 1867-1871.

[12] Piechota, H. J.; Dahms, S. E.; Nunes, L.S.; Dahiya, R.; Lue, T. F. and Tanagho, E. A. (1998 a). In-vitro functional properties of the rat bladder regenerated by the bladder acellular matrix graft. J Urol 159: 17171724.

[13] Piechota, H. J.; Dahms, S. E.; Probst, M.; Gleason, C. A.; Nunes, L. S.; Dahiya, R. Lue, T. F. and Tanagho, E. A. (1998 b). Functional rat bladder regeneration through xenotransplantation of the bladder acellular matrix graft. Br J Urol 81: 548-559.

[14] Ram-Liebig, G.; Meye, A.; Hakenberg, O. W.; Haase, M.; Baretton, G. and Wirth, M. P. (2004). Induction of proliferation and differentiation of cultured urothelial cells on acellular biomaterials. Br J Urol Int 94(6): 922927.

[15] Schultheiss, D.; Gabouev, A. I.; Cebotari, S.; Tudorache, I.; Walles, T.; Schlote, N.; Wefer, J.; 


\section{International Journal of Science and Research (IJSR) \\ ISSN (Online): 2319-7064 \\ Index Copernicus Value (2013): 6.14 | Impact Factor (2015): 6.391}

Kaufmann, P. M.; Haverich, A.; Jonas, U.; Stief, C. G. and Mertsching, H. (2005). Biological vascularized matrix for bladder tissue engineering: Matrix preparation, reseeding technique and short-term implantation in a porcine model. J Urol 173(1): 276280.

[16] Sutherland, R. S.; Baskin, L. S.; Hayward, S. W. and Cunha, G. R. (1996). Regeneration of bladder urothelium, smooth muscle, blood vessels and nerves into an acellular tissues matrix. J Urol 156(8): 571-577.

[17] Yang, S. X.; Shen, F. J.; Hu, Y. F.; Jin, H. M. and Wang, L. L. (2005). Experimental bladder defect in rabbit repaired with homologous bladder extracellular matrix graft. $C M J$ 118(11): 975-960

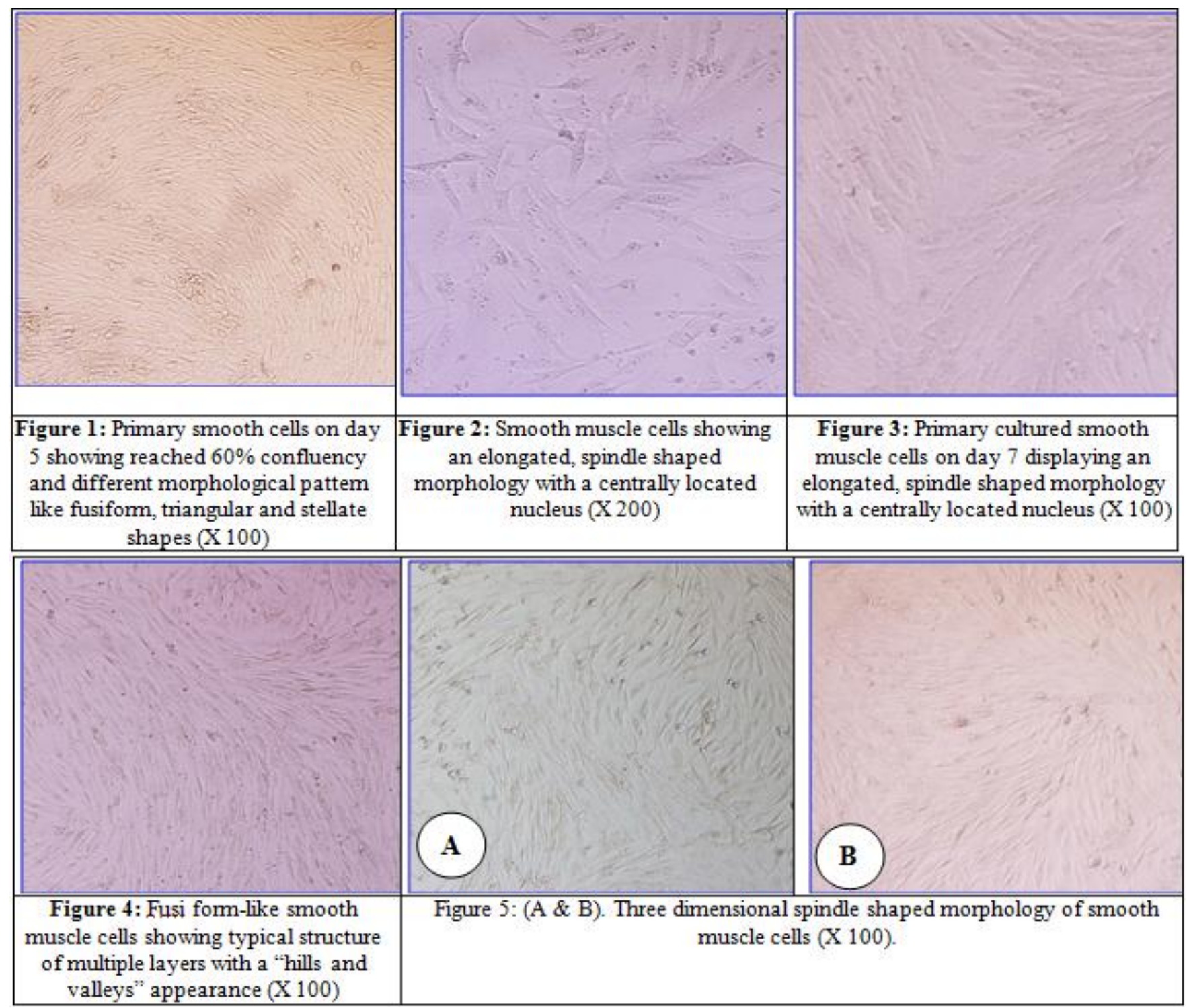


International Journal of Science and Research (IJSR)

ISSN (Online): 2319-7064

Index Copernicus Value (2013): 6.14 | Impact Factor (2015): 6.391
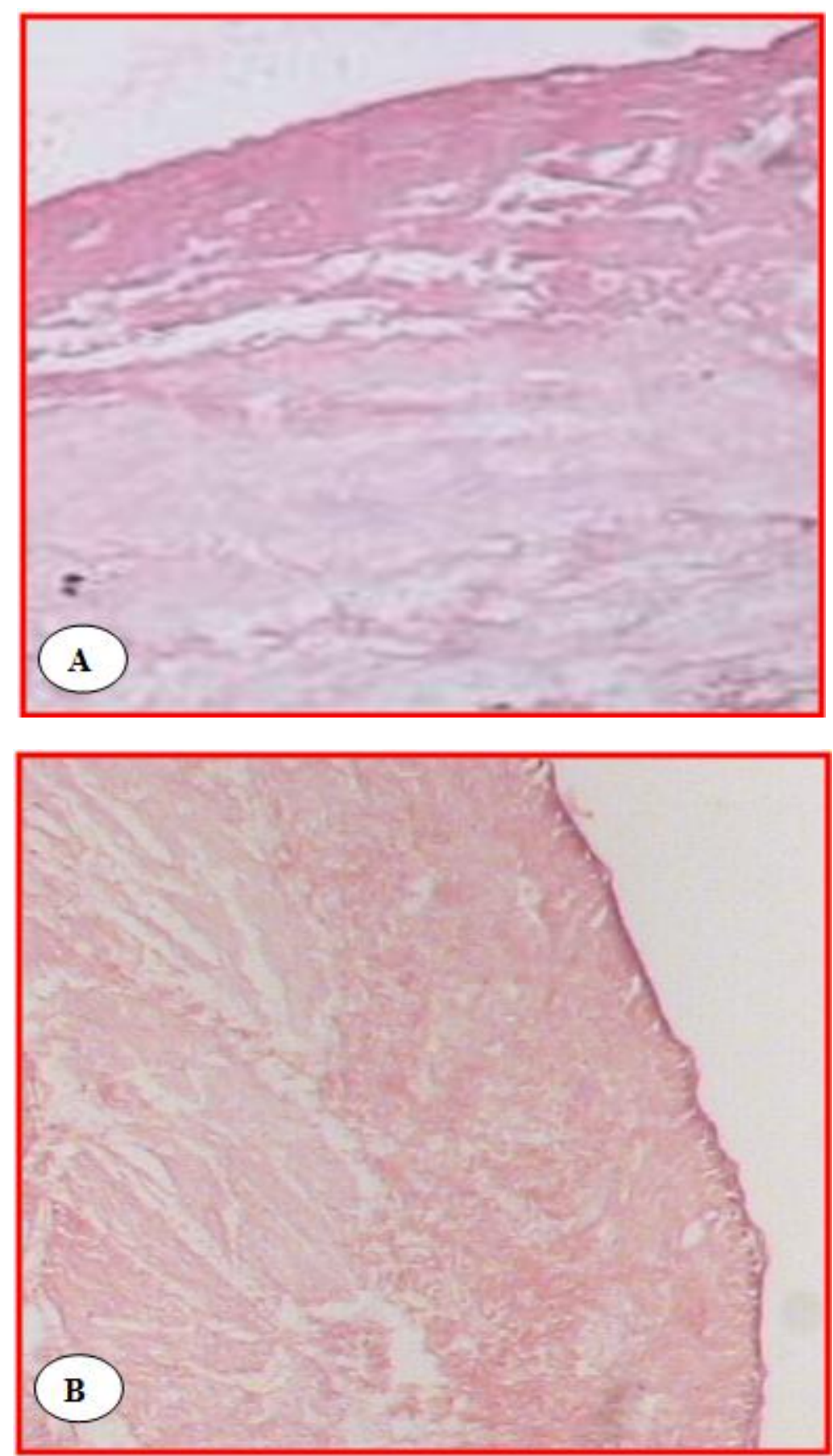

Figure 6: (A \& B). Histological BAM showing complete a cellularity with normal collagen fibres arrangement (H\&E X100) 